\title{
Atmospheric Pressure Spray Mass Spectrometry: Characteristics of the Mass Spectra of Saccharides
}

\author{
Minoru SAKaIRI ${ }^{\dagger}$ and Hideki KambarA \\ Central Research Laboratory, Hitachi Ltd., Kokubunji, Tokyo 185, Japan
}

\begin{abstract}
The characteristics of the saccharide mass spectra by the atmospheric pressure spray (APS) method have been investigated. The APS mass spectrum depends on the temperature of the capillary from which fine droplets are produced. Under low-temperature operation, only cationized molecules of saccharides are obtained. Under hightemperature operation, however, fragment ions due to the cleavage of glycosidic bonds appear in the APS mass spectra in addition to cationized molecules. These ions produced by high-temperature operation are very useful for obtaining information concerning the saccharide structure. The APS mass spectra of several saccharides containing cationized molecules and fragment ions are presented.
\end{abstract}

Keywords Atmospheric pressure spray mass spectrometry, saccharide

We have developed an atmospheric pressure spray (APS) ionization method..$^{1-3}$ Since this technique can be operated under atmospheric pressure and can accommodate a high flow rate $(1 \mathrm{ml} / \mathrm{min})$ of conventional liquid chromatography, this technique is very promising as an interface of liquid chromatography/ mass spectrometry. In this method, fine droplets from a heated capillary are directly introduced into a mass analyzing region through a differential pumping region to produce protonated and/or cationized molecules of thermolabile and nonvolatile compounds. Especially, intense cationized molecules of saccharides can be obtained by this very simple interface. It is, therefore, very interesting and important to clarify the characteristics of mass spectra of saccharides by the APS method, since a saccharide analysis is one of the most important targets in biochemistry. 4,5 This paper reports on the temperature dependence of the mass spectra obtained by the APS method, and also describes the characteristics of the APS mass spectra of saccharides.

The structures of the saccharides investigated in this paper are shown here.

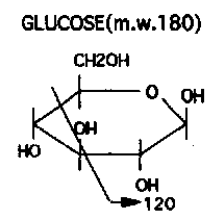

FRUCTOSE(m.w.180)

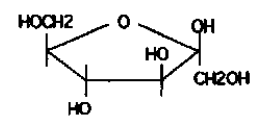

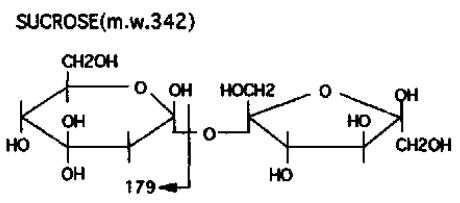

MALTOSE(m.w.342)

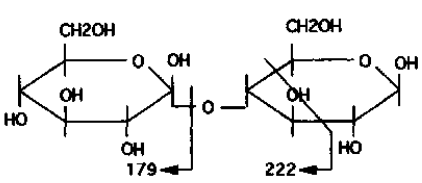

RAFFINOSE(m.w.504)

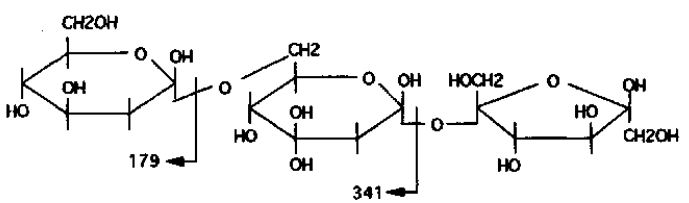

MALTOTRIOSE(m.w.504)

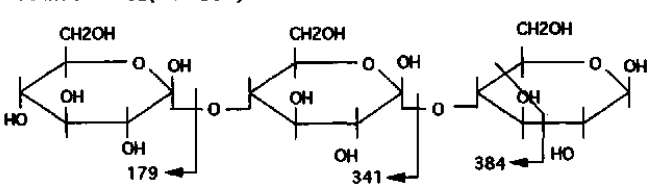

STACHYOSE(m.w.666)

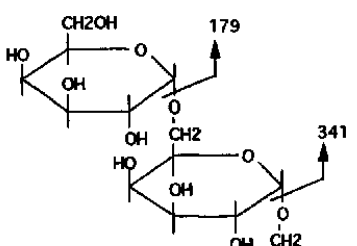

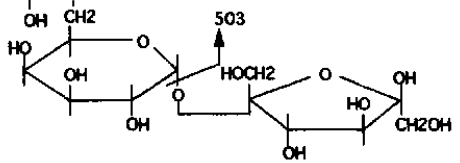

$\dagger^{\dagger}$ To whom correspondence should be addressed. 


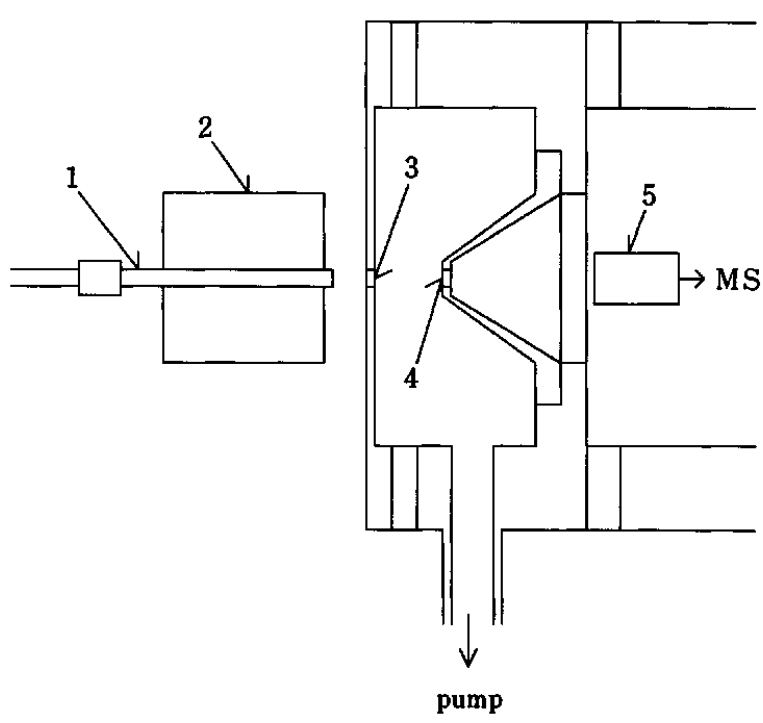

Fig. 1 Schematic diagram of the atmospheric pressure spray ion source. (1) stainless-steel capillary, (2) stainless-steel block, (3) nozzle, (4) skimmer, (5) electrostatic lens.

\section{Experimental}

The details of the liquid chromatograph/atmospheric pressure spray mass spectrometric system have already been described elsewhere. ${ }^{1,3}$ A schematic diagram of the APS ion source is shown in Fig. 1. In this system, produced fine droplets from a heated stainless-steel capillary which is brazed to a stainless-steel block are directly introduced into a mass analyzing region through differential pumping regions in order to obtain ions. The stainless-steel block can be indirectly heated by cartridge heaters and is temperature-controlled. The precise temperature control of the block $\left( \pm 2^{\circ} \mathrm{C}\right)$ is very important for the reproducibility of the mass spectra. In the differential pumping region, evacuated to about 1 Torr by a mechanical pump, the drift voltage can be applied in order to increase the ion transmission efficiency and to dissociate cluster ions produced by adiabatic expansion.

The mass spectra of saccharides were measured by a flow injection analysis method without using a column. A ten microliter sample solution containing $200 \mathrm{pmol}$ of each sample was injected into the sample injector. One hundred percent water was used at a flow rate of $1 \mathrm{ml} /$ $\min$ as the mobile phase. The temperature of the stainless-steel block was set to $480 \pm 2^{\circ} \mathrm{C}$ for all of the measured compounds.

All of the samples of saccharides were purchased from Sigma Chemical Co. (St. Louis, MO, USA).

\section{Results and Discussion}

Temperature dependence of the APS mass spectrum

Figure 2 shows the variation in the total ion intensity of

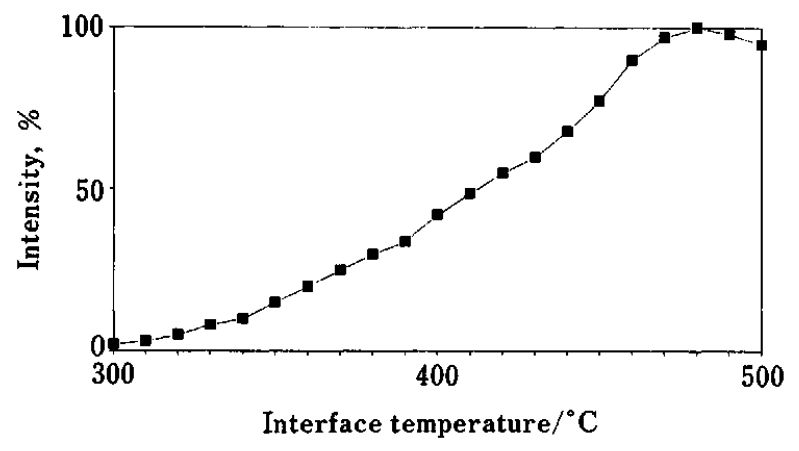

Fig. 2 Variation in the total ion intensity with the stainlesssteel block temperature.

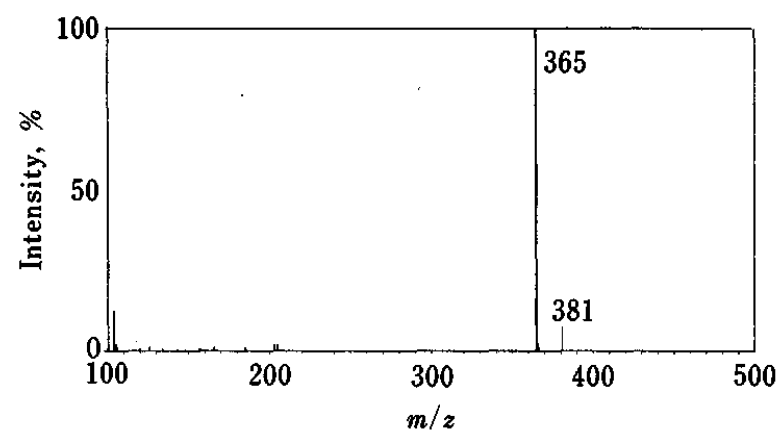

Fig. 3(a) APS mass spectrum of sucrose at a block temperature of $380^{\circ} \mathrm{C}$.

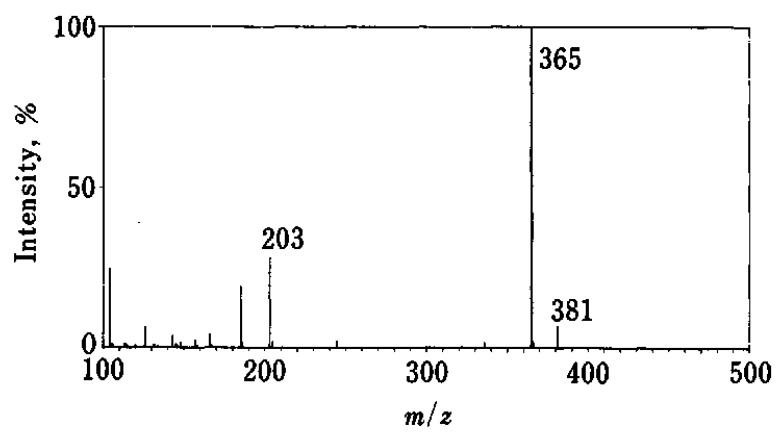

Fig. 3(b) APS mass spectrum of sucrose at a block temperature of $480^{\circ} \mathrm{C}$.

a $10^{-5} \mathrm{~mol} / 1$ sucrose solution with the temperature of the stainless-steel block, to which the stainless-steel capillary is brazed. It is clear that the ion intensity obtains a maximum at a block temperature of $480^{\circ} \mathrm{C}$. The tendency for a decrease in the ion intensity above $480^{\circ} \mathrm{C}$ is thought to be due to a loss of ions resulting from collisions of the ions with the capillary inner wall. ${ }^{1}$ The mass spectra of sucrose (m.w. 342) at block temperatures of 380 and $480^{\circ} \mathrm{C}$ are shown in Figs. 3(a) and 3(b), respectively. Sodiated molecules [M+Na] ${ }^{+}$at $m / z 365$ and potassiated molecules $[\mathrm{M}+\mathrm{K}]^{+}$at $\mathrm{m} / z \quad 381$ are observed with weak fragment ions in the mass spectrum at a block temperature of $380^{\circ} \mathrm{C}$, while the intense 
fragment ions at $m / z 203$ due to the cleavage of glycosidic bonds between the glucose and fructose moieties are obtained in addition to cationized molecules, such as $[\mathrm{M}+\mathrm{Na}]^{+}$and $[\mathrm{M}+\mathrm{K}]^{+}$, in the mass spectrum at a block temperature of $480^{\circ} \mathrm{C}$. The fragment ions at $\mathrm{m} / \mathrm{z} 203$ are considered to be produced by thermal decomposition accompanied by sodiation, together with the attachment of hydrogen. That is to say, the ions at $\mathrm{m} / z 203$ correspond to the structure of $\left[\mathrm{C}_{12} \mathrm{H}_{22} \mathrm{O}_{11}-\mathrm{C}_{6} \mathrm{H}_{11} \mathrm{O}_{5}+\right.$ $\mathrm{H}+\mathrm{Na}]^{+}$. The observed cationized molecules and the fragment ions are very useful, since it can be estimated that a sucrose molecule has a hexose-hexose structure from these ions.

Mono saccharides. Figures 4 and 5 show the mono saccharide mass spectra of D-glucose (m.w. 180) and Dfructose (m.w. 180), respectively. The mass spectrum of D-glucose shows sodiated molecules $[\mathrm{M}+\mathrm{Na}]^{+}$at $\mathrm{m} / z 203$ with several fragment ions at $m / z 143$ and so on, while the mass spectrum of $\mathrm{D}$-fructose shows intense $[\mathrm{M}+\mathrm{Na}]^{+}$at $m / z 203$ with weak fragment ions. We can, therefore, distinguish D-glucose from D-fructose by specific fragment ions, such as the ions at $m / z 143$, which are considered to be produced by a ring rupture of glucose molecules accompanied by sodiation $\left(\left[\mathrm{C}_{6} \mathrm{H}_{12} \mathrm{O}_{6}-\mathrm{C}_{2}-\right.\right.$ $\left.\mathrm{H}_{4} \mathrm{O}_{2}+\mathrm{Na}\right]^{+}$).

Di saccharides. It is difficult to distinguish maltose (m.w. 342) from sucrose (m.w. 342) in soft ionizations like FD and so on, since they have the same molecular weight. ${ }^{6,7}$ However, they can be easily distinguished from each other by comparing their APS mass spectra, since maltose produces intense fragment ions at $m / z 245$.

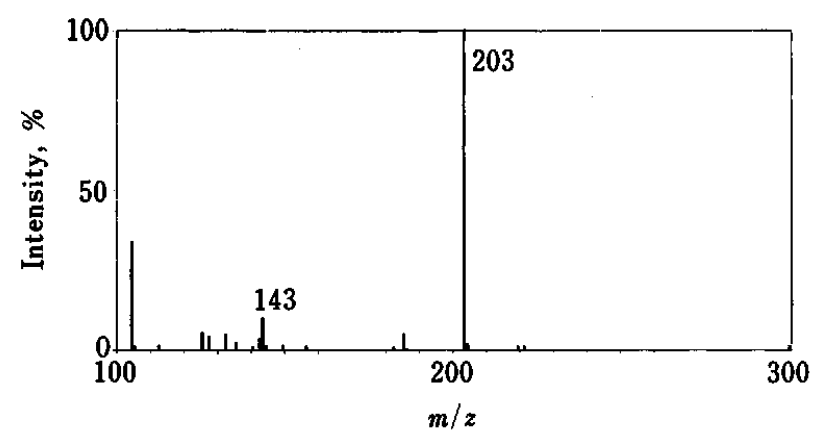

Fig. 4 APS mass spectrum of $\beta$-D-glucose.

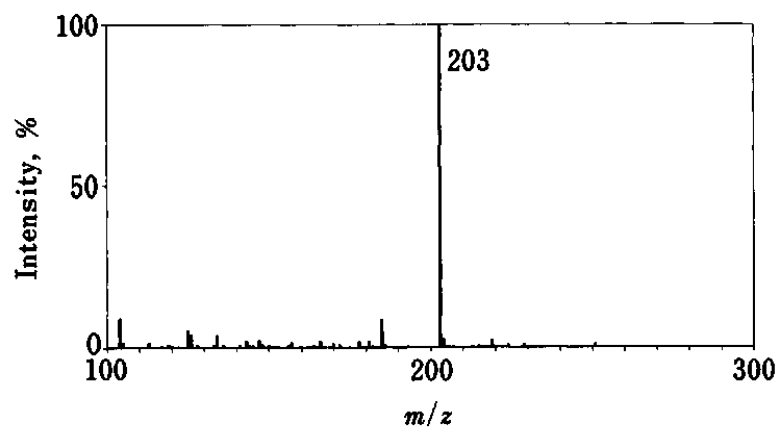

Fig. 5 APS mass spectrum of $\beta$-fructose.
Figure 6 shows the APS mass spectrum of maltose, in which the intensity of the fragment ions at $\mathrm{m} / z 245$ are comparable to that at $m / z 203$. However, the fragment ions at $\mathrm{m} / \mathrm{z} 245$ are hard to observe in the mass spectrum of sucrose, as shown in Fig. 3(b). It is likely that the fragment ions at $m / z 245$ are also produced by a ring rupture accompanied by sodiation $\left(\left[\mathrm{C}_{12} \mathrm{H}_{22} \mathrm{O}_{11}-\mathrm{C}_{4} \mathrm{H}_{8-}\right.\right.$ $\left.\mathrm{O}_{4}+\mathrm{Na}\right]^{+}$).

Tri saccharides. The APS mass spectra of raffinose and maltotriose, which have the same molecular weight (m.w. 504), are shown in Figs. 7 and 8, respectively. It is noteworthy that only maltotriose produces several intense fragment ions above $m / z 365$, such as ions at $m / z$ 407. Therefore, raffinose is distinguishable from maltotriose due to the fragment ions above $m / z 365$. It is anticipated that the ions at $m / z 407$ are produced by the ring rupture of maltose molecules accompanied by

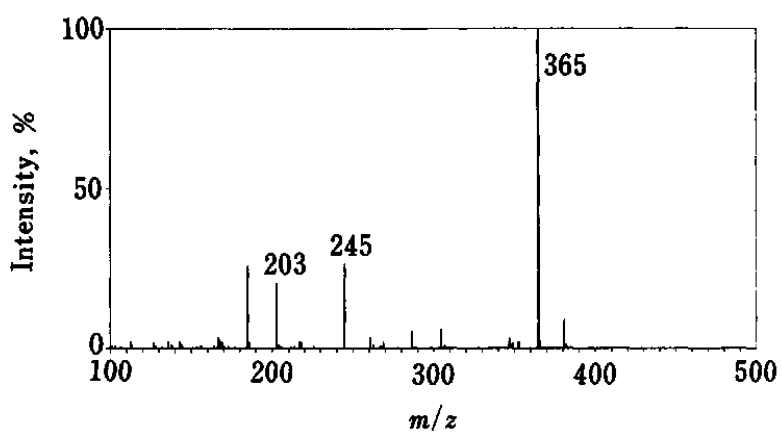

Fig. 6 APS mass spectrum of maltose.

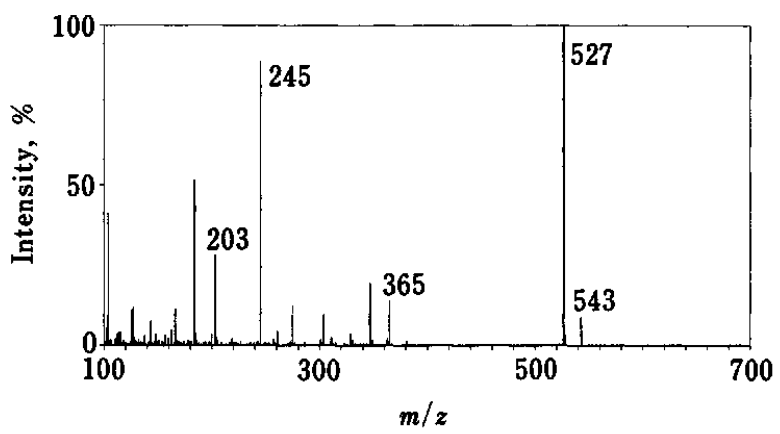

Fig. 7 APS mass spectrum of raffinose.

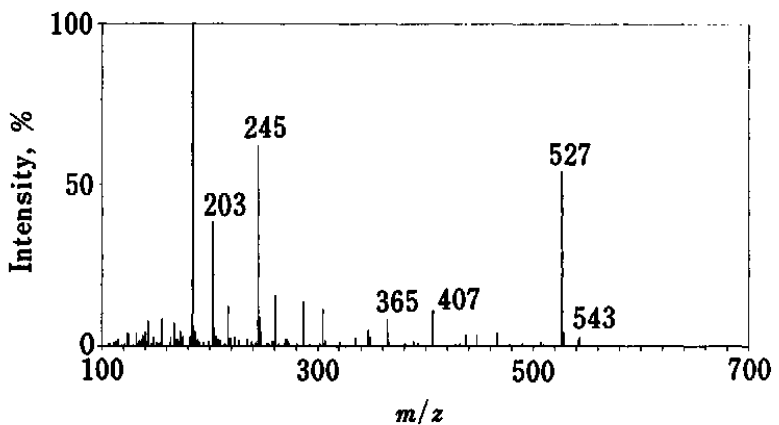

Fig. 8 APS mass spectrum of maltotriose. 


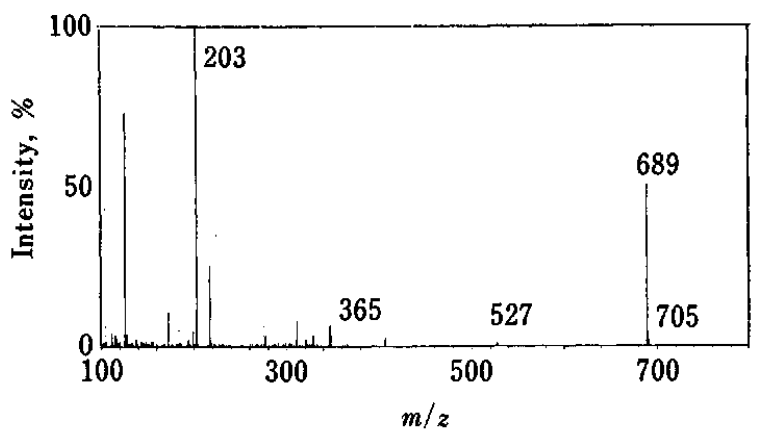

Fig. 9 APS mass spectrum of stachyose.

sodiation $\left(\left[\mathrm{C}_{18} \mathrm{H}_{32} \mathrm{O}_{16}-\mathrm{C}_{4} \mathrm{H}_{8} \mathrm{O}_{4}+\mathrm{Na}\right]^{+}\right)$.

In both cases of raffinose and maltotriose, it seems reasonable to conclude that these molecules have a hexose-hexose-hexose structure based on the ions at $m / z 527,365$ and 203.

Tetra saccharide. The APS mass spectrum of a tetra saccharide (stachyose) is shown in Fig. 9. Similarly, it can be assumed that a stachyose molecule has a hexosehexose-hexose-hexose structure based on the ions at $m / z 689,527,365$ and 203.

As shown above, an APS mass spectrum depends on the temperature of the capillary from which fine droplets are produced. Under high-temperature operation, fragment ions mainly due to the cleavage of glycosidic bonds appear in the APS mass spectra, in addition to cationized molecules. These ions produced under hightemperature operation are very useful for obtaining information about the saccharide structure.

\section{References}

1. M. Sakairi and H. Kambara, Anal. Chem., 61, 1159 (1989).

2. M. Sakairi and H. Kambara, Mass Spectrosc., 37, 68 (1989).

3. M. Sakairi, Doctoral Thesis (The University of Tokyo), January, 1989.

4. V. Ginsberg, Methods Enzymol., 1982, 83.

5. V. Ginsberg, Methods Enzymol., 1987, 138.

6. H. D. Bechey, "Principle of Field Ionization and Field Desorption Mass Spectrometry", Pergamon, Oxford, 1977.

7. H. Kambara and S. Hishida, Anal. Chem., 53, 2341 (1981).

(Received June 30, 1993)

(Accepted September 13, 1993) 